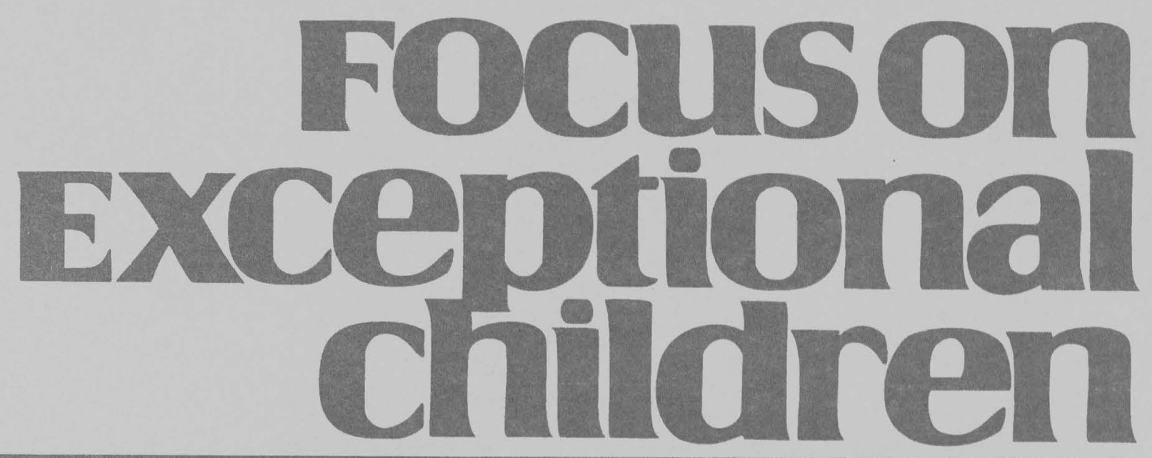

\title{
Sociocultural Scaffolding as a Means Toward Academic Self-Regulation: Paraeducators as Cultural Brokers
}

\author{
Robert Rueda and Michael Genzuk
}

One of the major developments in both general and special education has been the "cognitive revolution" and its impact on instructional practice. While perceptual-motor training and related "ability training" models predominated in earlier special education interventions (Meyers \& Hammill, 1990), research failed to substantiate their impact on academic achievement (Arter \& Jenkins, 1979; Kavale \& Forness, 1985). Subsequently, this "ability training" perspective has been replaced by a cognitive orientation to learning that is now increasingly dominant in both general and special education. The reason for the increased influence of the cognitive model in special education practice is the realization that many of the learning problems that characterize students with mild learning disabilities are due to problems in the use of learning strategies and self-regulation (Brown, 1978; Brown, Armbruster, \& Baker, 1986; Brown \& Campione, 1986).

Contemporary cognitive psychology focuses on the cognitive processes that learners use to actively make sense of incoming information. More specifically, this perspective focuses on an individual learner's use of strategies for problem solving, his or her metacognitive awareness about when, where, and why to use specific strategies, strategies for self-monitoring, how the individual stores and uses background knowledge, and motivational factors (especially beliefs) that impact learning (Gagné, Yekovich, \& Yekovich, 1993; Pressley \& McCormick, 1995). The impact of this perspective on the education of students with mild learning disabilities has been substantial (Graham \& Harris, 1993; Reid, Hresko, \& Swanson, 1996). Students with mild learning problems have been shown to be passive, nonstrategic learners with poor self-monitoring and an often inadequate store of background knowledge. As a result, various interventions have been developed that focus on one or more of these specific aspects. These powerful interventions emphasize the active construction of knowledge and meaning, with a goal of self-regulation, to address poor academic achievement.

An example of a successful intervention from this orientation is the reciprocal teaching method for reading comprehension instruction described by Palincsar and Brown (1986). Using explanations and modeling, four strategic activities were taught to groups of

\footnotetext{
Robert Rueda is a professor of Psychology in Education at the University of Southern California. Michael Genzuk is a clinical associate professor at the University of Southern California. This article was adapted from New Ways of Looking at Learning Disabilities: Connections to Classroom Practice, published by Love Publishing Company, 2001.
} 
at-risk students to increase reading comprehension: selfquestioning about the main idea, summarizing, predicting, and clarifying difficult sections of the text. These strategic activities then became a script to guide discussions about the text, where students took turns playing teacher. Discussions centered on the effectiveness of the text summary, the clues used to make predictions, students' differing interpretations of the text, and differing use of strategies. Variations of this procedure have been successful with a wide variety of students with learning disabilities. A review of other successful applications of the cognitive orientation in reading, writing, and other areas can be found in Reid and Kuykendall (1996).

\section{COGNITION AND LEARNING: SOCIOCULTURAL CONSIDERATIONS}

As powerful as the cognitive psychology framework has been in reformulating thinking about the nature of learning problems and promoting active instruction, the cognitive

\section{Focuson
Exceptional children}

ISSN 0015-511X FOCUS ON EXCEPTIONAL CHILDREN (USPS 203-360) is published monthly except June, July, and August as a service to teachers, special educators, curriculum specialists, administrators, and those concerned with the special education of exceptional children. This publication is annotated and indexed by the ERIC Clearinghouse on Handicapped and Gifted Children for publication in the monthly Current Index to Journals in Education (CIJE) and the quarterly index, Exceptional Children Education Resources (ECER). The full text of Focus on Exceptional Children is also available in the electronic versions of the Education Index. It is also available in microfilm from Serials Acquisitions, National Archive Publishing Company, P.O. Box 998, Ann Arbor, MI 48106-0998. Subscription rates: individual, \$42 per year; institutions, \$56 per year. Copyright (C) 2007, Love Publishing Company. All rights reserved. Reproduction in whole or part without written permission is prohibited. Printed in the United States of America. Periodical postage is paid at Denver, Colorado. POSTMASTER: Send address changes to:

$$
\begin{gathered}
\text { Love Publishing Company } \\
\text { Executive and Editorial Office } \\
\text { P.O. Box } 22353 \\
\text { Denver, Colorado } 80222 \\
\text { Telephone (303) 221-7333 }
\end{gathered}
$$

\section{EDITORIAL BOARD}
Lisa Dieker
University of Central Florida
Paula Maccini University of Maryland
Marleen Pugach
University of Wisconsin-Milwaukee
Carrie E. Watterson Editor
Stanley F. Love
Publisher

model has some shortcomings. For example, one characteristic of the cognitive orientation has been the search for universals in human cognition and learning (Strauss, 1996). One of the consequences of this goal has been a de-emphasis on context and on sociocultural factors in learning and development. Recently, researchers and theorists have begun to acknowledge the limitations that this narrow focus has imposed on research and the development of relevant interventions (Greeno, 1998; Rogoff \& Chavajay, 1995) and have pointed to sociocultural theory as a useful expansion of the learning research (Keogh, Gallimore, \& Weisner, 1997).

An especially relevant addition to sociocultural theory is found in work by Rogoff and colleagues. Sociocultural theory in general, and the work by Rogoff and colleagues (Rogoff, 1994, 1995; Rogoff, Baker-Sennett, La Casa, \& Goldsmith, 1995) in particular, focus on the social, cultural, and interactional aspects of learning, cognition, and development. Briefly, Rogoff proposed a view of learning and development as a dynamic process of transformation of participation in a given community of learners. Rogoff's framework orients the researcher to answer such questions as, What are the activities in which people participate? Why and with whom and with what do they participate? How do the activity, its purpose, and peoples' roles in it transform? How do different activities relate to one another currently, historically, and prospectively?

Participation in any sociocultural activity occurs on many planes or levels of interaction. Rogoff (1995) suggested that a complete account of learning and development must take into account a minimum of three levels or planes of development: the personal plane, involving individual cognition, emotion, behavior, values, and beliefs; the interpersonal or social plane, including communication, role performances, dialogue, cooperation, conflict, assistance, and assessment; and the community or institutional plane, involving shared history, languages, rules, values, beliefs, and identities. Sociocultural theory in general emphasizes that these three planes are inseparable. Moreover, language is the primary force that defines and connects these planes. While one plane might be "foregrounded" for a particular study or analysis and the other planes "backgrounded," a complete account of learning and development needs to consider all three simultaneously.

In practice, the smallest unit of analysis that contains all three planes is the activity setting, or the "who, what, when, where, why, and how" of the routines that constitute everyday life. Although perhaps confusing at first, an activity setting can simply be seen as a more concrete way of talking about what is often called "context." What is often harder to understand, however, is that adopting the activity setting as one's unit of analysis means that the individual is no longer the exclusive focus. The target for study or intervention is 
rather the individual in interaction with others in a specific activity setting. This unit of analysis, along with the practice of "foregrounding" and "backgrounding" various planes of development for different purposes, offers a useful way of talking about the social and cultural features of learning.

One of the important implications of this view of learning and cognition as consisting of interacting planes of development is that all of the planes must be taken into account when building and implementing a comprehensive instructional program. Most public discussions about improving school performance and academic achievement fail to consider this interaction. Moreover, as powerful as existing cognitive theory and interventions are, one shortcoming is that they focus almost exclusively on the individual (Greeno, 1998). This relatively narrow focus has been especially prominent in special education, where the focus on individual deficits is deeply embedded in tradition, law, and practice (Trent, Artiles, \& Englert, 1998).

\section{FROM THEORY TO PRACTICE: A FOCUS ON DIVERSE LEARNERS}

As schools have become increasingly diverse, they have been forced to deal with cultural and linguistic factors in learning, often in the absence of well-developed theoretical frameworks for guiding practice. Research has substantiated the important role that sociocultural factors play in academic success for diverse learners and how neglect of these factors can be detrimental to childrens' school careers (Au \& Kawakami, 1994).

Crago, Eriks-Brophy, Pesco, and McAlpine (1997), as well as others, have described how sociocultural factors can impede learning when they are ignored. Their work suggests that the discourse and interaction that take place in the classroom are the foundation for learning and that the social events in which these factors are embedded and through which meaning is co-constructed by participants are key factors in successful academic achievement. Thus, instances of miscommunication may originate and manifest themselves in cultural differences regarding language use, participation, and interaction structures in the classroom as well as differences in the nature and use of narrative forms and other aspects of literacy. As the authors pointed out, these factors are often mediated by the imbalance in power relationships based on culture, race, and socioeconomic status. In short, learning takes place in the context of social relationships in the classroom, and both success and failure can be considered socially organized activities.

For learners from diverse sociocultural and linguistic backgrounds, these factors are especially critical. A classic example of how these considerations can make a difference in educational success is found in the KEEP reading program implemented in Hawaii, which was designed to make reading instruction culturally compatible with the backgrounds of native Hawaiian children (Au, 1997; Au et al., 1986; Tharp \& Gallimore, 1988). In addition to changing the focus of instruction from low level to more challenging content (word identification vs. comprehension), specific sociocultural features of students' everyday lives were incorporated into the instructional program. Specific elements addressed included opportunities to use out-of-school discourse forms such as cooperative production of responses by two or more children ("talk story"), modifications in the exercise of authority, attention to fair allocation of students' speaking time, and other features. Dramatic gains in students' achievement resulted from the use of these classroom features.

There are many other examples that also substantiate the importance of sociocultural factors in learning in both special education and general education settings. In theoretical terms, the issue of cultural congruence in instruction ( $\mathrm{Au} \&$ Kawakami, 1994) belies the importance of the planes of development that extend beyond the individual. For English learners and other diverse learners, the interpersonal and community planes of development take on increased importance. The argument being made here is that while students with learning problems benefit from cognitively based selfregulatory strategies, of equal importance are consideration of students'existing sociocultural knowledge and the role of linkages and connections to out-of-school communityrelated factors. In short, contextualized instruction is good instruction. Although many teachers are equipped to provide cognitive scaffolding to assist their students to increase their self-regulatory repertoires, relatively few are equipped to provide the "sociocultural scaffolding" that is so critical for many students.

\section{CONCEPTUALIZING EVERYDAY KNOWLEDGE}

One useful way of thinking about children's backgrounds and home environments as resources and not as deficits is found in the work on funds of knowledge (Moll \& Greenberg, 1990). This body of research studies households' social and community histories and attempts to derive instructional innovations and insights from such analysis. The basic concept is that every household is an educational setting in which the major function is to transmit knowledge that enhances the survival of its dependents. One way to look at "funds of knowledge" is as a guidebook of sorts of the essential information and strategies that families and communities need to maintain their well-being and continued survival. In other words, funds of knowledge are wide 
ranging and abundant. They are central to the family and to the relationship of the family to others in the community. They have been referred to as the nuts and bolts for survival (Moll \& Greenberg, 1990).

Given what is known about the contextualized nature of teaching and learning, these social relationships provide a motive and a context for applying and for acquiring knowledge. The key point is that funds of knowledge are constructed through daily events or activities. That is, funds of knowledge are not possessions or idiosyncrasies of people in the family but are characteristics of people in an activity (Moll \& Greenberg, 1990). Knowledge is therefore obtained and constructed by the children, not imposed by the adults. This kind of knowledge is most often content or knowledge based and is rarely insignificant. Funds of knowledge usually matter; that is, they are authentic. For it is only when the content of an interaction is significant or necessary that people are motivated to establish the social contexts for the transfer or the use of knowledge and other resources. It is these social relationships that are so intriguing and carry with them the potential to form the foundation for academic learning. Without specific, deliberate attention to these social relationships and persons in activities, it is very easy for educators to underestimate the abundance of funds of knowledge available in ethnic or working-class environments. It is this third plane of development, in Rogoff's terms, that is so often neglected in curriculum and instructional practice.

Many educators and researchers continue to undervalue the background knowledge of nonmainstream children. For many at-risk children, especially those in special education, background knowledge and experience are often viewed as information from which the student must be rescued rather than as reserve of knowledge that can foster the child's cognitive growth (Gonzalez et al., 1993). Funds of knowledge are available in all households and communities regardless of families' years of formal schooling or the prominence that families assign to school-based literacy. Yet this type knowledge and the forms of transmission families use for sharing it rarely make their way into classrooms in any substantive way (Moll \& Greenberg, 1990). Funds of knowledge represent a major, undeveloped resource for academic instruction that many schools have not learned to tap.

Lending support to this contention, researchers have noted an increase in motivation and engagement in schools where students, especially those labeled at risk, are able to develop personal bonds with adults (Foster, 1994; McLaughlin \& Talbert, 1990; Wigfield, Eccles, \& Rodriguez, 1998). For example, a personalized style and an intimate and nurturing relationship between Latino teachers and pupils, characterized as cariño (affectionate kindness), has been identified as one of several influential elements in classrooms that exhibit high degrees of co-membership and success (Cazden, 1988).

\section{THE ROLE OF PARAEDUCATORS IN EFFECTIVE INSTRUCTIONAL PROGRAMS}

In seeking ways to address this issue in diverse classrooms, we have focused our recent work on paraeducators. The nation's nearly 500,000 paraeducators working in $\mathrm{K}-12$ classrooms embody a promising source of prospective instructors for the nation's diverse student population in both special and general education. Paraeducators are school employees whose responsibilities are instructional in nature or who deliver other services to students. They work under the supervision of teachers or other professional personnel who have the ultimate responsibility for educational programs (Pickett, 1994). Often they live in the community in which the school is located and are familiar with students' home language and discourse forms, whereas teachers often reside elsewhere and may not speak the language. Paraeducators can therefore potentially bring a wealth of community and relevant background knowledge to their practice, attributes that are greatly needed in today's diverse classrooms (Haselkorn \& Fideler, 1996).

As suggested earlier, students may have fewer opportunities to learn when school lessons and other activities are conducted, or socially organized, in a manner that is inconsistent with the values and norms of their home culture. A related hypothesis is that students of diverse backgrounds will have better learning opportunities if classroom instruction is conducted in a manner that is congruent with the culture of the home. This type of instruction has been labeled culturally compatible instruction (Jordan, 1985) and culturally responsive instruction (Erickson, 1984).

Zapata (1988), discussing shared identity in teaching and learning, argued that instructors more often predicate their instructional choices on their own ways of learning than base them on how their students learn. He argued that instructors generally pattern their teaching based upon the methods of learning that were successful for them.

In the majority of cases, especially those where the teachers and their students are from different sociocultural backgrounds, shared identity of teachers and students is rare. However, if learning is influenced by one's sociocultural environment, then teachers and students from similar backgrounds have a greater likelihood of having shared understandings and similar background knowledge. Accordingly, teachers with these shared understandings may be better prepared than teachers from other backgrounds to meet the learning needs of an ever growing proportion of the school population (Zapata, 1988). 


\section{PARAEDUCATORS AS TEACHERS: SOME CLASSROOM EXAMPLES}

We are currently engaged in research examining the instructional activities of Latino paraeducators in classrooms with English language learners. Because of the trend toward reducing special education placements, most of these classrooms, which are not special education placements, include students who have been diagnosed as having learning disabilities. We are particularly focused on how the funds of knowledge that these paraeducators bring to the classroom impact their teaching behaviors. Although we are collecting a variety of measures, we are relying primarily on field notes of classroom observers visiting classrooms on numerous occasions over an extended period of time to capture ongoing instructional events.

Although this work is at an early stage, we have begun to identify various ways that the paraeducators' funds of knowledge enter into their teaching. Some of our observers (graduate students who are often of the same ethnic and language background as the children and paraeducators), for example, have noted the almost "grandmotherly" quality that some of the paraeducators evoke and its effect on children's engagement. The following excerpt from a first-grade Spanish language arts class illustrates this point (observer's comments in italics):

\begin{abstract}
When children gave the correct response, the paraeducator would say "muy bien" [very good] or "excelente" [excellent] with a very enthusiastic and encouraging facial expression and voice. (This behavior seemed to increase childrens' attention and interest.) During this exercise, one young boy was biting his fingernails to which the paraeducator said as she took his hand away from his mouth, "No te comas el dedo" [Don't eat your finger]. (She did this in an authoritative, motherly fashion, in a way that reminded me of the way teachers interact with children in my hometown in Mexico, and it seemed that the children perceived the paraeducator with high respect and appreciation.)
\end{abstract}

Other data from our research also illustrate the simple but effective way that discourse forms can accomplish this effect. For example, we have found that it is common for paraeducators to use terms of endearment, such as "mi amor" (literally, my love), which are common, affectionate forms of address normally used by parents and grandparents. It may be that in the efforts to professionalize teaching, an emphasis on maintaining professional distance has become a value that discourages this type of interaction with students. The following excerpt from our field notes from this same first-grade Spanish language arts class illustrate other ways that these special forms of knowledge come into play:

The final exercise was in a dictation of words. The paraeducator would pronounce a word and the children were to write the words down on a sheet of paper. In one occasion a boy was missing a letter, so the paraeducator got near the boy's ear and pronounced the dictated word "sorpresa" [surprise] with an emphasis on the letter he was missing, which was the second " $r$ " in the word. After two more pronunciations of the word by the teacher and a bit of thinking on the child's part, he included the missing letter. Both the child and the paraeducator had a smile. To another boy who spelled the word "encontrar" [to find] wrong, the paraeducator repeated the word out loud. The boy paused to think, and the paraeducator encouraged him by saying "Tu 10 puedes hacer" [You can do it]. The boy attempted to correct the word but is wrong again. The paraeducator says "come on Raul," encouraging the boy, and pronounces the word one more time. The boy writes it correctly this time, to which the paraeducator enthusiastically responds "muy bien" [very good], and the boy smiles. Another boy had a problem writing the word "ustedes" (you-plural). He had written the letter "a" instead of the second letter "e" in the word, but after a short pause to reason, the boy was successful. To this the paraeducator knocked on the boy's head and said "knock, knock". The paraeducator said "Excelente, si usa la cabeza, muy bien" [Excellent, if you use your head that is very good]. (All this was done in a very positive/comic voice to which the young boy and his classmates expressed themselves with a big smile.)

This excerpt illustrates several interesting features of the way that this paraeducator manages instructional activities. For example, it is important to notice how errors were handled. At the beginning of the excerpt, where a student was missing a letter in his response, the paraeducator chose not to publicly correct the student. Rather, she physically approached the child and pronounced the complete word emphasizing the missing letter, and he was able to produce the correct answer. This approach is a significant change from the question-answer-evaluate sequence seen in so many classrooms.

With a second student, she used a different strategy, providing simple encouragement and confidence in the child's ability to produce the correct answer. Rather than producing the answer herself, or calling on another student, or rebuking the child for not knowing the answer, she chose to provide encouragement and confidence in the child's abilities, and he was able to succeed.

Finally, at the end of the excerpt, the paraeducator affectionately knocked on a child's head in a comedic fashion after the child made an error. Although the students were amused, the paraeducator managed to communicate that the boy needed to think harder, but she did so in a way that did not humiliate the student or penalize his error.

For this paraeducator, the social relationships she maintains with the students are of great importance. She uses a variety of strategies to engage her students, many of which are rooted in the cultural and linguistic shared knowledge that she has with these students. This type of cultural and 
linguistic scaffolding that we have repeatedly noted in our observations appears to be a key aspect of maintaining engagement for these students, who for a variety of reasons are at risk for low academic achievement.

It is likely that other aspects of classroom instruction and interaction are also influenced by the backgrounds of the paraeducators we are studying. For example, many researchers have begun to study teachers' belief systems as important mediators of their classroom teaching practices. We have found intriguing examples of how the belief systems of paraeducators and teachers differ. In describing the nature of learning problems exhibited by their students with learning disabilities, teachers in our study have tended to refer to factors such as "visual-motor processing" and other related constructs that are focused on presumed within-child deficits. Paraeducators, conversely, have tended to focus more on specific knowledge of the family related to such factors as unemployment, economic problems, the influence of older siblings, and the presence of gangs in the neighborhood.

We have only begun to categorize and catalog the ways that the paraeducators in our study are able to utilize their background knowledge and experiences in their teaching. Even at this early stage, however, it is clear that the cultural and language-based scaffolding on which they draw are important resources that can help provide a bridge to those students who need it. While cognitive interventions are clearly important in promoting academic success, our research has supported the contention that there is a social side to learning that must be addressed as well. It is important to note that we are not arguing that one must be of the same ethnic or racial group to be a successful teacher of diverse students. However, we are arguing that special attention needs to be paid to recognizing and validating the unique backgrounds that many students bring to school and that would otherwise be seen as deficits and impediments to learning. Unfortunately, the type of teaching knowledge that we have been documenting is rarely recognized or promoted in teacher training programs.

While many teachers do not share the backgrounds of their students, they should be able to learn about the communities in which they work. A useful resource that they can use for instructing students in diverse classrooms is the pool of paraeducators who can help bridge the academic content of the school with the social and discourse knowledge of students from diverse backgrounds. In short, paraeducators have enormous potential to bridge the three planes of development referred to earlier.

\section{A NOTE ON COLLABORATIVE PRACTICE}

It is paradoxical that at the same time that paraeducators represent an important addition to the classroom, they are often undervalued by the teachers and schools in which they work. Although still in its very early stages, our study suggests that many paraeducators are assigned low-level activities and are given little freedom in terms of instructional activities. It is rare to find a truly collaborative relationship where the paraeducator and teacher discuss and plan instruction, each contributing his or her own expertise. Many paraeducators report a wide gap in terms of status, which is made concrete in a variety of ways. Although there are notable exceptions, we have found that many teachers do not take full advantage of the special skills and expertise that paraeducators might contribute. While paraeducators do not have the formal training and credentials that teachers do, they do have a great deal to contribute especially in diverse classrooms. It would be wise for teachers to consider carefully the role of paraeducators in their classrooms and to evaluate whether there are better ways to incorporate and build on this resource.

\section{REFERENCES}

Arter, J. A., \& Jenkins, J. R. (1979). Differential diagnostic prescriptive teaching: A critical appraisal. Review of Educational Research, 49, 517-555.

Au, K. H. (1997). Ownership, literacy achievement, and students of diverse cultural backgrounds. In J. T. Guthrie \& A. Wigfield (Eds.), Reading engagement: Motivating readers through integrated instruction (pp. 168-182). Newark, DE: International Reading Association.

Au, K. H., Crowell, D. C., Jordan, C., Sloat, O. C. M., Speidel, G. E., Klein, T. W., \& Tharp, R. G. (1986). Development and implementation of the KEEP reading program. In J. Orasanu (Ed.), Reading comprehension: From research to practice (pp. 235-252). Hillsdale, NJ: Erlbaum.

Au, K. H., \& Kawakami, A. J. (1994). Cultural congruence in instruction. In E. R. Hollins, J. E. King, \& W. C. Hayman (Eds.), Teaching diverse populations: Formulating a knowledge base. (pp. 5-24). Albany, NY: State University of New York Press.

Brown, A. L. (1978). Knowing when, where, and how to remember: A problem of metacognition. In R. Glaser (Ed.), Advances in instructional psychology (Vol. 1, pp. 77-165). Hillsdale, NJ: Erlbaum.

Brown, A. L., Armbruster, B. B., \& Baker, L. (1986). The role of metacognition in reading and studying. In J. Orasanu (Ed.), A decade of reading research: Implications for practice (pp. 49-75). Hillsdale, NJ: Erlbaum.

Brown, A. L., \& Campione, J. C. (1986). Psychological theory and the study of learning disabilities. American Psychologist, 14, 1059-1068.

Cazden, C. B. (1988). Classroom discourse: The language of teaching and learning. Portsmouth, NH: Heinemann.

Crago, M. B., Eriks-Brophy, A., Pesco, D., \& McAlpine, L. (1997). Culturally-based miscommunication in classroom interaction. Language, Speech, and Hearing Services in Schools, 28, 245-254.

Erickson, F. (1984). School literacy, reasoning, and civility: An anthropologist's perspective. Review of Educational Research, 54, 525-546. 


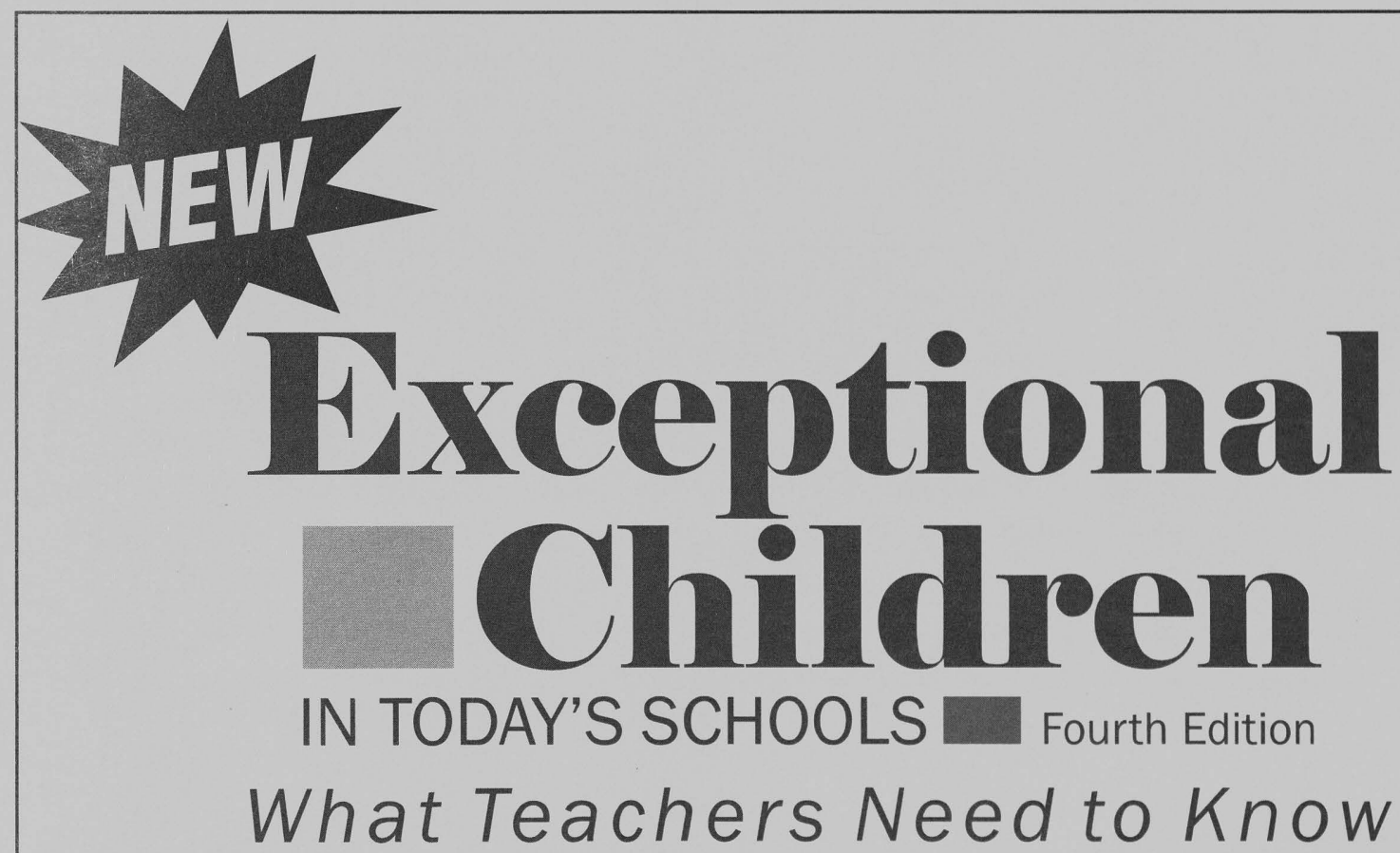

\section{Edward L. Meyen and Yvonne N. Bui}

Here is a new book all teachers will welcome as a resource when working with children. It is designed to fit the needs of college professors, students, and the staff development needs of school districts and individual teachers.

The text includes both the print version and a cutting-edge e-book providing a wide array of features including self-assessments, activities, case studies, handouts, and audio of each chapter to hear or download to your MP3. The book covers students with mild, moderate, and severe disabilities. It is interactive in every way, not just a print and digital text. It is perfect for on-line courses.

This exciting new approach to learning is responsive to both No Child Left Behind and the new 2004 IDEA reauthorization. Readers will find the most current information on inclusive classrooms, transition, diversity, collaboration, and much more. Order your copy today.

978-0-89108-317-7 / paperback / 416 pages / copyright 2007 
Foster, M. (1994). Effective black teachers: A literature review. In E. R. Hollins, J. E. King, \& W. C.Hayman (Eds.), Teaching diverse populations (pp. 225-241). Albany, NY: State University of New York Press.

Gagné, E. D., Yekovich, C. W., \& Yekovich, F. R. (1993). The cognitive psychology of school learning. New York: HarperCollins College Publishers.

Gonzalez, N., Moll, L. C., Floyd-Tenery, M., Rivera, A., Rendon, P., Gonzales, R., \& Amanti, C. (1993). Teacher research on funds of knowledge: Learning from households (Educational Practice Reports 6). Santa Cruz, CA: University of California, National Center for Research on Cultural Diversity and Second Language Learning.

Graham, S. \& Harris, K. R. (1993). Self-regulated strategy development: Helping students with learning problems develop as writers, Special Issue: Strategies Instruction. Elementary School Journal, 94, 169-181.

Greeno, J. G., and the Middle School Mathematics Through Applications Project Group. (1998). The situativity of knowing, learning, and research. American Psychologist, 53, 5-26.

Haselkorn, D., \& Fideler, E. (1996). Breaking the class ceiling: Paraeducator pathways to teaching. Belmont, MA: Recruiting New Teachers.

Jordan, C. (1985). Translating culture: From ethnographic information to educational program. Anthropology and Education Quarterly, 16, 105-123.

Kavale, K. A., \& Forness, S. R. (1985). The science of learning disabilities. San Diego, CA: College Hill Press.

Keogh, B. K., Gallimore, R., \& Weisner, T. (1997). A sociocultural perspective on learning and learning disabilities. $L D$ Research and Practice, 12, 107-113.

McLaughlin, M., \& Talbert, J. (1990). Constructing a personalized school environment. Phi Delta Kappan, 72, 230-235.

Meyers, P. L., \& Hammill, D. D. (1990). Learning disabilities: Basic concepts, assessment practices, and instructional strategies. Austin, TX: PRO-ED.

Moll, L. C., \& Greenberg, J. B. (1990). Creating zones of possibilities: Combining social contexts for instruction. In L.C. Moll (Ed.), Vygotsky and education: Instructional implications and applications of sociohistorical psychology (pp. 319-348). New York: Cambridge University Press.

Palincsar, A. S., \& Brown, A. L. (1986). Interactive teaching to promote independent learning from text. The Reading Teacher, 39, 771-777.

Pickett, A. L. (1994). Paraprofessionals in the education workforce. Washington, DC: National Education Association.

Pressley, M., \& McCormick, C. B. (1995). Cognition, teaching, and assessment. New York: HarperCollins College Publishers.
Reid, D. K., Hresko, W. P., \& Swanson, H. L. (Eds.) (1996). Cognitive approaches to learning disabilities. Austin, TX: PRO-ED.

Reid, D. K., \& Kuykendall, M. (1996). Literacy: A tale of different belief systems. In D. K. Reid, W. P. Hresko, \& H. L. Swanson (Eds.), Cognitive approaches to learning disabilities (pp. 497-544). Austin, TX: PRO-ED.

Rogoff, B. (1994). Developing understanding of the idea of communities of learners. Mind, Culture, and Activity, 1, 209-229.

Rogoff, B. (1995). Observing sociocultural activity on three planes: Participatory appropriation, guided participation, and apprenticeship. In J. V. Wertsch, P. Del Rio, and A. Alvarez (Eds.), Sociocultural studies of mind (pp. 139-164). Cambridge, UK: Cambridge University Press.

Rogoff, B., Baker-Sennett, J., Lacasa, P., \& Goldsmith, D. (1995). Development through participation in sociocultural activity. In J. Goodnow, P. Miller, \& F. Kessel (Eds.), Cultural practices as contexts for development. (Pp. 45-65). San Francisco: Jossey-Bass.

Rogoff, B., \& Chavajay, P. (1995). What's become of research on the cultural basis of cognitive development? American Psychologist, 50, 859-877.

Strauss, S. (1996). Confessions of a born-again constructivist. Educational Psychologist, 31, 15-21.

Tharp, R., \& Gallimore, R. (1988). Rousing minds to life: Teaching, learning, and schooling in social contexts. Cambridge: Cambridge University Press.

Trent, S. C., Artiles, A. J., \& Englert, C. S. (1998). From deficit thinking to social constructivism: A review of theory, research, and practice in special education. In P. D. Pearson \& A. Iran-Nejad (Eds.), Review of research in education (Vol. 23, pp. 277-307). Washington, DC: American Educational Research Association.

Wigfield, A., Eccles, J.S., \& Rodriguez, D. (1998). The development of children's motivation in school contexts. In P. D. Pearson \& A. Iran-Nejad (Eds.), Review of research in education (Vol. 23, pp. 73-118). Washington, DC: American Educational Research Association.

Zapata, J. T. (1988). Early identification and recruitment of Hispanic teacher candidates. Journal of Teacher Education, Vol. 2, 19-23.

The work described herein was supported under the Education Research and Development Program, PR/Award No. R306A60001, the Center for Research on Education, Diversity \& Excellence, as administered by the Office of Educational Research and Improvement (OERI), National Institute on the Education of At-Risk Students (NIEARS), U.S. Department of Education (USDE). The contents, findings, and opinions expressed in this chapter are those of the authors and do not necessarily represent the positions or policies of OERI, NIEARS, or the USDOE. 